\title{
From Passive Viewers to Content Generators: Audience Role on TV Programs and Online Media
}

\author{
Edlira Gjoni \\ Tirana University, Tirana, Albania
}

\begin{abstract}
Media content in the digitalised world is nowadays able to reach bigger number of audience than ever before. The content is frequently reproduced online via social media and web portals. The growing number of media platforms and the smartphones presence in millions of consumers' hands, has also stimulated growth in the level on interactivity between the media and the audience. Newspapers, radio, television and even specific programs are now entering the cross-media processes that enables direct communication with the audience, and allows participation of content-users in many ways. Audience is increasingly contributing to design content, production and also distribution in social media. This paper examines the dimensions of audience participation in five Albanian television channels and their online websites. Via the exploratory analysis used as a methodology to examine over three hundred audience participation encounters, the article discusses the audience behaviour and reaction on these particular websites on a period of five weeks across October to December 2016. The analysis focuses on audience active participation on specific sections of the websites. Interesting results emerge as the audience shows different perspectives via its participatory activities online, which can be classified into four main roles: consumers, citizens, commentators, and activists. The paper discusses the characteristics and insinuations of each of these emerging roles.
\end{abstract}

Keywords: audience studies, consumers, commentators, audience participation, citizens

\section{Introduction}

\section{Audience Participation in Popular Media Webpages}

Internet has changed the way media works. It has shaped the structure and operating model of press and television. Number of TV channels has grown significantly worldwide, hand in hand with alternative communicating platforms. These engaging platforms are increasingly distributing content and have influenced significantly in the traditional media's decision to search innovative formats, distribution, presence, and business models in the audio-visual industry (Curtin, 2009, p. 9). One of the driving forces behind this change remains the race to capture the audience and to keep up with the challenging competition for audience rates.

With the Internet and fast growth of social media users, the audio-visual industry faces a bigger challenge to find new ways to keep hold of the audience, which has now discovered the power of participation and engagement via the social media platforms such as Facebook, Twitter or YouTube (Doyle, 2010, p. 432). Televisions and newspapers have already shifted to online competition, where the biggest challenge is no longer the news speed or information depth, but the variety and alternative points of view for the news of the

Edlira Gjoni, Ph.D. Candidate, Department of Social Work, Faculty of Social Sciences, Tirana University. 
day; or any other feature that attracts audience, enhances views' participation and satisfies their need to feel involved in the process. These developments are happening whilst multi-platform media researchers believe that broadcasters consider these platforms as a reliable defensive approach to stay close to the audience and advertisers (Doyle, 2015; Bauman \& Hasenpusch, 2016)

Apart from the official webpage, many TV programs are now using their own website platform, providing thus a more interactive opportunity and experience for the viewers. The online platforms provide a richer experience for the audience, which is proving to increasingly look for participation opportunities, such as voting, discussions, social networks entertainment services, on-demand programs and videos, and more clearly, to interact and contribute to the media content (Adams, 2008).

Various sections are now made available by online platforms of the media outlets, in the effort to give an opportunity to the audience to engage, share, comment, criticise, add content, evaluate, vote, score, to promote, to elaborate own material and to get involved with various stages of the meaning-making process in the media, maximising the use of the Internet. Researchers such as Colapinto (2010), Roscoe (2004), and Doyle (2010) suggest that Internet and mobile will have an even stronger role in the content distribution of broadcasters. Multiplatform media are already providing alternative transmitting routes which are less expensive than traditional broadcasts (Dvorak, 2012).

The role and importance of audience participation changed when the Internet became widely used and smart phones were introduced to the world. Following the increasing trends of audience involvement, Caldwell (2006) argues that the broad range of experiences and participation of the television audience highlights the need for a broader definition of the media texts and content. The new reception of the TV programs has pushed the media to increase the opportunities of audience participation through feedback and other forms of engagement. Media programs are now produced with a distribution perspective in mind, serving online trends and audience expectations, and hopefully, their engagement in content sharing through the excessive applications available for use by the audience (Deery, 2003).

\section{Theoretical Framework}

In Communication Studies, audience participation takes different meanings. In the digital era we are living, media studies are interlinked with the technological development, mainly to the participatory dimension of this new environment for the media (Press \& Williams, 2010). Schaefer (2011) examined participation in the light collaboration and social interaction it generates, whilst Castells (2010) sees participation as a new formulation of power, centred on the collective actions of active citizens. The citizen goes beyond consuming a text, an image, a product, and as Usher (2011, p. 265) argues, the citizen is engaged in contributing with self-expressed and evident levels of understanding, communication, cultural, political and social engagements, considering their participation as a civic responsibility.

Online participation and audience rise in media engagement processes brought in new concepts and viewpoints for the audience, which is now considered as a key communication factor with its user-generated-content feature and user to user interaction (Curran, Fenton, \& Freedman, 2012). The optimistic views on audience participation go as far as arguing that active audience is able to produce and share content, overcoming the need and dependency on traditional media (Rosen, 2006), which is discussed in the case of active participation later in this paper.

In this research, audience participation refers to the feedback that audience members provide through 
various means of communication offered by the broadcasters, i.e., voting by SMS in reality shows, or calling in a talk show to give own opinion. The new participation tools provide more opportunities to the audience not only to participate, but also to produce content and to distribute it freely to others (Singer et al., 2011; Villi, 2012; Domingo, 2008).

Media websites, online versions of newspapers and web portals are combining updates, news and video streaming services with their social network sites, mostly via Facebook, and Twitter. This combination has led to what is now called Social Television, where remote viewers separated in time and space can freely interact with each-other via social media and Internet (Cesar \& Geerts, 2011). Level of interaction is high and enabled by features such as live chat, list of what friends are watching, recommended pages and links, sharing options, suggested videos based on statistics and trends of personal pages connected to personal accounts, etc. All these changes led to reviewing the concept of the audience as a whole.

In her excessive studies on the subject, Livingstone (1998) refers to the audience as the established relationship among public and the media. Siapera (2004) looks at the audience in the light of television consuming, and classifies it into six categories: citizens, consumers, educations receptors, spectators, fans and web surfers. Earlier communication studies analysed audience either as consumers or citizens (Butsch, 2008; Livingstone, 2011; Couldry, 2001; Syvertsen, 2004; Webster \& Phalen, 1997) and today, audience is also seen as client and player (Costera Meijer, 2005).

Audience consumption of the media has increased mostly via smartphones, mobile, personal computers, laptops and other fixed devices. Videos and links available online have now a volume that surpasses the information and access available to users only a few years ago (Dowland, 2016). The new technological developments have indeed provided new opportunities of audience participation, where the public reaches the media faster and more significantly, by commenting online, by sharing content, by labelling, reacting or criticising news (Steensen, 2011), or by providing alterative information and by defining success of entertainment programs (Jakubowicz, 2008).

The new participating forms of online engagement for the audience, have also changed some patterns of participation created by the traditional media. Data shows that voting programs are experiencing a decrease in the number of audience engaged in the program flow, and as Nightingale and Dwyer (2006) argue, this is mostly related to the commercial characteristics of the voting system, where media presenters exhibit persuasive selling rhetoric, seeking to engage as many viewers as possible in the programme.

Recent developments of reality shows indicated that they have added chat discussions and fan based forums, where the audience tends to engage more. There are cases where audience members participate via donations, in-kind contribution or other types of funding (free services for show participants), obtaining in return advantages of fame, profit or career success (Marshall, 1997).

Audience was very fast to start using the technological devices, whilst traditional media followed somehow slower and in a more conservative way (Siapera, 2004). TV channels still seem to be competing for numbers of audience rates, with little attention on how viewers use their content, what is their knowledge and to what extent they can be involved with the media. There are TV channels which still perform in the traditional way of addressing the audience as consumers, offering content through a screen which is accessed from home or from other technological devices. Broadcasters are interested in this kind of content distribution because it is profitable in terms of market share. Herreros (2004) argues that television channels do not see audience participation as a communicative model, but as a good business model to better finance their programming. The 
concept of the consumer associates the media with the business concept, where the viewer is under constant persuasion pressure to buy the advertised products.

\section{Media and Television in Albania}

According to the Internet World Statistics (2016), Albania, a country of 3 million people, has 1.8 million Internet users, of which about $70 \%$ are Facebook users. Over one million unique visitors watch YouTube and other video links on average 21.3 hours per month (ComScore, 2016). Despite the migration of use from desktop to mobile, online users have increased, due to mobile phone owners, who now demand audio-visual content and enriched viewing experience, depending on the type, screen, size and device where they watch (Bachmayer, Lugmayr, \& Kotsis, 2010). Online media consumption has therefore increased, same as the participatory cases of the audience, engaging and at times, even setting the agenda for the media (see Social Activism case in this paper).

The most active consumers are the so-called digital natives, who have the tendency to watch programs on the Internet rather than TV. They see audience participation tools as a natural feature of the media to serve their expectations. The new mind-set and participatory behaviour of the digital-natives represents a new request and need for a transformation of the traditional policies of many public and commercial broadcasters, where audience plays a central role. However, this shift in the role of the audience has not mirrored big changes in the way media executives and producers design their strategies for the involvement of the new audience types.

Recent audience measurement (Telemetrix, 2016) suggest that the main players on the television market in Albania are Top Channel, TV Klan, News 24, Ora News and Vizion Plus, which are also in the focus of this research. The Albanian public Broadcaster TVSH, and its range of channels on music, sports and arts, remain in the low rank for the third year since the measurements are made public (Mavise, 2016). The country has seven news channels and about 45 local television channels. There are also two satellite operators, Digitalb and Tring Digital, offering a wide range of thematic, from film and music, to sports, travelling and arts. The TV channels address an audience of just about 3 million people. Distribution of TV services is significant, with an estimated $50 \%$ of TV holders subscribed to a pay TV, satellite and terrestrial services. The main TV stations included in this research have their own webpages where viewers can turn to for news and additional information or advertisement, but not for interacting with the respective media.

The new digitalisation process in the country has increased the competition and the market fragmentation, which is pushing TV companies to seek new programming and advertising strategies targeting their audience. Audience share is not available publically.

Similarly to other countries, audience participation has developed fast in the past three years. TV programs and channels provide participatory tools to attract audience comments and opinions. These tools include online comments, e-mails to the audience, SMS, free calls, YouTube videos, fan chats, barometers and public tolls. Despite these developments and new ways of inclusion, the relationship between Albanian media and their audience remains weak. Interviews made during the research for this paper suggest that online participation initiatives are not efficient yet to the level of content creation. They still need to work on the transparency of audience participation and the media should have clearer goals when developing and offering participatory tools.

In Europe, audience gained a significant and sudden role in the media with the new approaches which gave them a chance to get involved in the production of programs (Carpentier, 2001). In Albania, this became 
evident with programs like "Njerëztëhumbur", where audience members were directly involved in helping find their missing persons, or in entertainment shows like "KëngaMagjike", "Big Brother", or "Dancing with the stars", where viewers were invited to vote for their favourite contestant. Syvertsen (2004) argued that this approach was embraced mostly by the commercial and private media, with public broadcasters dismissing this type of participation formats as being too commercial, suffering in terms of quality and being too populist.

With the smartphone's booming and presence, both public and commercial media are now increasing the number of applications and platforms which enable viewers to participate in the program and even to renovate, create and share content. The Web 2.0 enabled Internet users to generate own content, helping thus viewers to become not only consumers, but also producers and distributors of reality shows (Holmes, 2004), and sometimes, even in newsrooms, where texts, photos and videos sent by users are assessed and at times, broadcasted by traditional media in their news editions (Garcia-Aviles, 2010).

\section{Methods}

This paper examines audience participation in the digital age and analyses the audience response to the new tools and developments offering new opportunities to become part of the media content. Comparative analysis is used to reflect the wide range of actors and platforms included in the broadcasting industry, and to look carefully into the variables and matchings in the selected cases.

The analyses is centred into the participative tools available on the homepages, Facebook accounts and specific sections designed and offered with the aim to encourage audience participation. These include any service or tool that is used to connect the medium with its audience. Garcia-Aviles (2011) classifies audience participation into four groups: (1) Debate encouraging tools, such as forums, chat services, comments, blogs, and box for automatic e-mails among others; (2) Content sharing tools, Facebook, Twitter; (3) Specific applications to allow sending large files like videos, pictures, audio, text to TV programs or newsrooms; (4) Story generating content, such as ratings, surveys or polls, with a news story that might emerge from it.

Using the exploratory analysis, over 300 audience interaction and participation were examined in five commercial television channels in Tirana and on their websites, during eight weeks from October to December 2016: Top Channel, TV Klan, Ora News, Vizion Plus and News 24. The paper examines the interaction offered by the specific tools made available by the TV channels in an attempt to foster audience participation. This interaction includes participation in the studio, discussions among audience members and ideas leading to content creation. Qualitative analysis of the selected program and their program was made, bearing in mind the limitations it brings by excluding criteria such as geographical provenance or residence of the audience, age group, gender division or education level of the participants. Additionally, the qualitative method generalizes the results, and encounters difficulties in being validated without the support of missing quantitative analysis.

\section{Analysis}

The case studies on how the audience interacts with the media highlighted elements that are related to a number of media user's characteristics, the way they make a meaning and the impact it has on their reaction as content users. As Figure 1 shows, the most repeated features of the audience interaction with the media match the definitions of audience as consumers, with 58\% of type-reaction on the audience engagement observed; $27 \%$ match the commentator definition, $11 \%$ fall into the category of content-generating citizens, and only $4 \%$ of the engagement cases observed math the description of audience as activists, enabling social mobilisation 
and shaping media's broadcasting behaviour in selected cases. This section of the analysis demonstrates a selection of particular cases of participation into each category and gives insights into their insinuations.

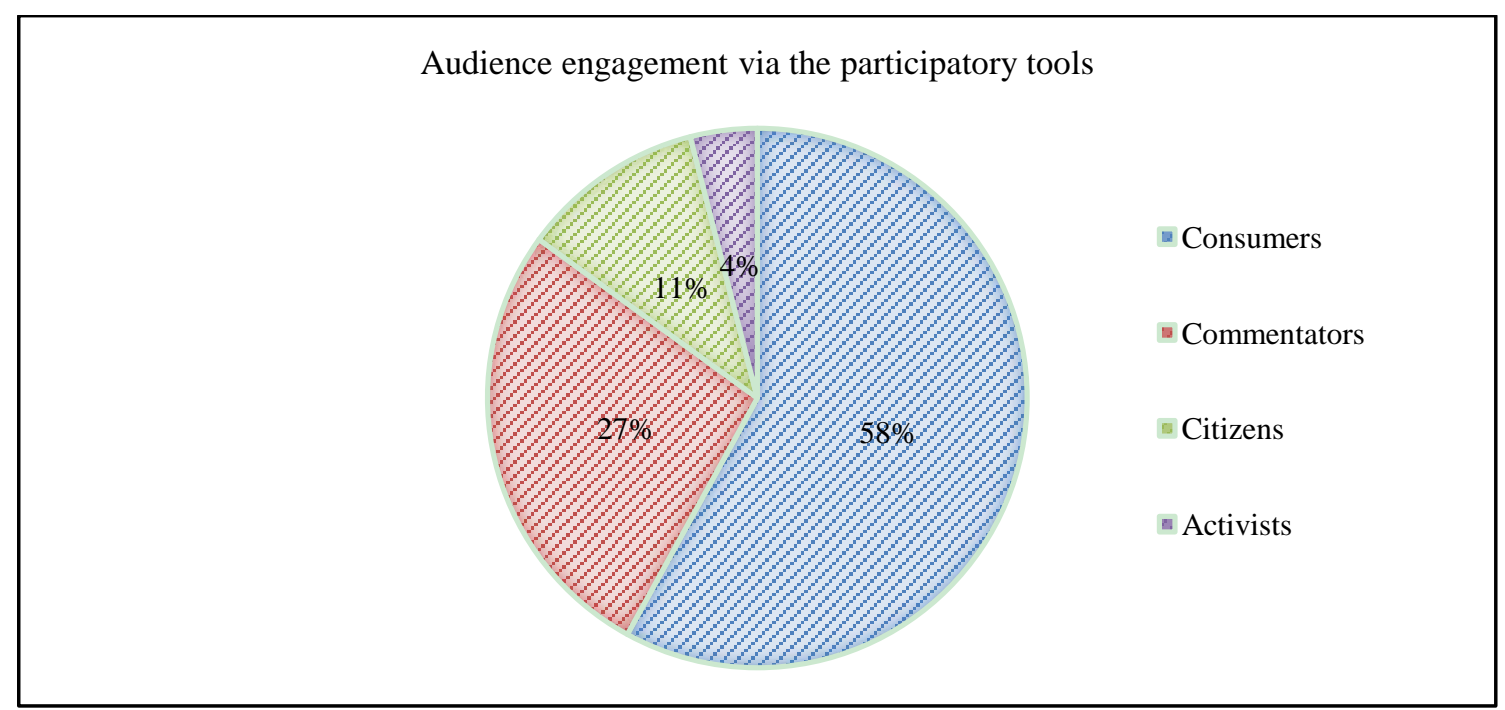

Figure 1. Type of audience engagement in the multi-platform media programs in five TV stations in Albania from October-December 2016.

\section{Audience Members as Consumers}

Media treats viewers as consumers in all those cases when it makes every effort to increase participation through consumerism elements, buying and selling techniques like sending SMS, interacting with ads, participating in commercials, in lottery draws, live betting or pay-per-view. For some networks, audience consumption trends are important, as they adapt their program to attract these consumers among the viewers.

Three out of five websites analysed for this paper provide merchandising corners and links to online shopping. Top Channel and TV Klan do not include advertisement in their homepage. But they attempt heavily to engage the audience in purchasing lottery tickets to be drawn (i.e., TV Klan, and if the phone rings, in order to win, the audience member should answer the phone by saying "Telebingo", which is the name of the program). Another feature is encouraging shopping in a specific supermarket chain which offers cost-based lottery on the 1st week of January live at this specific television (Top Channel for Big Market). Vizion Plus advertises the product from its own media company (Tring Digital), which is in this view seen as new source of income. News 24 and Ora News both advertise private banks and other private service providers, showing success stories from other costumers and encouraging audience to click on the links provided into their webpage.

Table 1

Addressing the Audience as a Consumer: Trends of Using Ads Online

\begin{tabular}{llllll}
\hline & TV Klan & Top Channel & Ora News & News 24 & Vizion + \\
\hline Adds on the webpage & - & - & $\sqrt{ }$ & $\sqrt{ }$ & - \\
Add for own products & - & - & $\sqrt{ }$ & $\sqrt{ }$ & $\sqrt{ }$ \\
\hline
\end{tabular}

Two cases of another participation activity can be observed at the News 24 webpage where viewers are encouraged to click and participate in discount offers from one private hospital and one private bank. The webpage offers the viewers the possibility of interacting instantly with the two private providers with a special 
discount for the media webpage users.

\section{Commentators, the Biggest Trend for the Online Media}

Media effect on the audience has different views from academics, and it is very much linked to some characteristics of the audience, such as economic status, education, experience and social environment among others. The effect and role of the media remains unknown until the audience is involved and active, both in research and in media communication. Audience participation is believed to improve the effectiveness of gaining and using information. Communication researchers believe that active engagement of audience in the public discourses can be enhanced through interaction with online media (Carpenter, 2001; Brundilge, 2010, Koltay, 2011).

One way of interacting is commenting on news stories and other TV features, when the media allows it. In Albania, these comments rarely deal with uncovered or additional sides of the stories being discussed. These comments frequently focus on the moderator or program guests, with 187 out of 302 audience engagement encounters observed. This constitutes $61.9 \%$ of all comments examined for this paper at the online platforms for Opinion, Top-show, Tonight, Studio e Hapur and Oktapod. Commenting space for these programs is available on the Facebook pages only. On the official websites of the TV Channels broadcasting these programs, no participatory feature is provided.

Media provides in this sense a great opportunity to the viewers to interact, to ask questions, to give information, opinion, ideas. To be part of the content. But rarely are comments likely to be useful for other people.

It is interesting to notice how viewers bring very diverse viewpoint for the same story, depending considerably from their own way of making a meaning and interpreting television content, but also depending on the type of program. For example, in the Top Show program "Epoka Trump" (Trump Era), aired on the 10th of November at Top Channel, frequency of audience engagement and commenting is significantly smaller compared to other episodes of the same program, which is mainly designed as an entertainment show. In the limited number of comments, focus is given to personal feelings about the outcomes of the presidential elections in the USA. On the same thematic, TV Show Opinion, 9 November, for the same thematic (Trump and the American elections), comments are present, frequent and diverse, focusing on personal remarks about the guests, but there are also argumentative comments from knowledgeable viewers. This confirms the affinity of the program with current affairs trends, and the audience familiarity with and acceptance of the thematic selected.

In selected cases, the viewers' comments complement the discussion in the studio, or the news items, helping other readers to get a clearer pictures of what is being broadcasted. All Facebook pages and portals offer the platform for comments and discussion, where viewers can analyse items from multiple points of view, and can exchange information on given issues within the TV platforms. Examples include the integration of updates from Facebook pages into livestreaming, allowing commenting from the audience as they watch the TV content. This is a normal feature for the TV program Opinion at TV Klan, or for the entertainment show "Xing me Ermalin", again at TV Klan, where comments and questions from the Facebook page are included and discussed in the show, bringing thus audience participation in the program. "Zone e lire" in TV Klan reinforces the use of audience participation in this television by relying on SMS content from selected viewers, often linked to the moderator, who shares the content with the audience. 


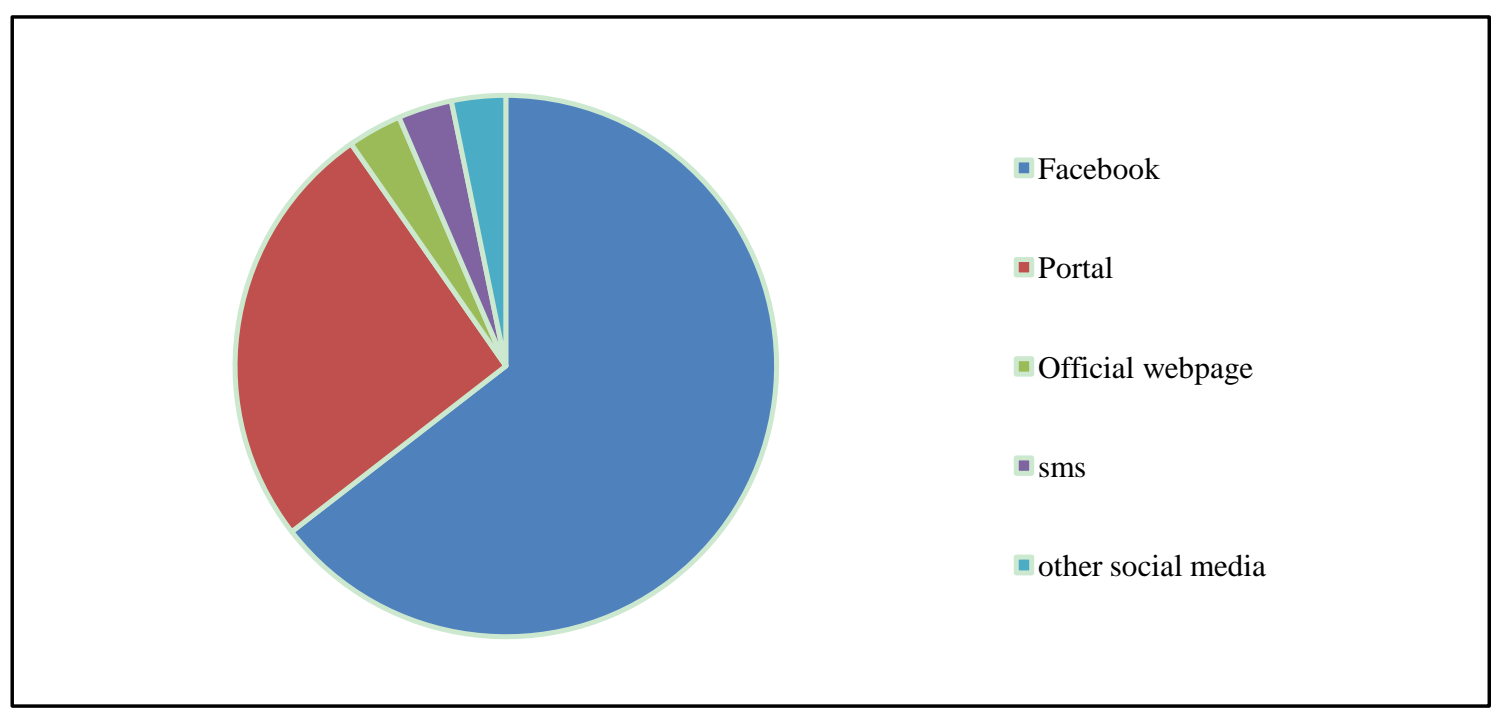

Figure 2. Audience prefered commenting platforms online.

As Figure 2 shows, the favourite platform of media engagement for the Albanian audience included in this research, remains Facebook, outnumbering all other platforms combined. Again, this research refers to TV programs only. Audience engagement for online news portals gives another panorama and requires a different examination. In that case, it is not Facebook, it's the commenting space underneath each news that attracts the highest frequency of comments in the Albanian media.

\section{Audience as Citizens, Ready to Commit and Control}

Commenting is considered as an action which is one step ahead of being a passive audience and consumer of media content. However, it not a sufficient step forward. Viewers can still contribute to economic, cultural, political and social processes. Scholars argue that the representative example of participatory dimensions of the new opportunities offered by the Internet, is the "Arab Spring", which brought in political change and development in North Africa and Middle East in 2010-2012. Social Network users were praised for reinforcing their individual strengths and influencing members of their communities to mobilize against their governments (Thorsen \& Allan, 2014).

By generating and sharing content on social media, key players from the public became crucial players in the public sphere. From the audience side, there is a clear understanding on the Internet's power as central agent in mobilising citizens (Anderson, 2011), however, changes are also favoured by the social, economic and cultural trends in each case.

Viewers now realise that they can contribute to monitoring decisions, messages, policies and governance, taking thus a role in the outcome of events that affect their lives. These type of audience members, the citizens, are discussed in this paper.

They are taking their place slowly, but are certainly present in the media. For example, Opinion regularly publishes various polls that encourage the audience to act in the citizen's role by giving their opinion, mostly on current affairs. Top Channel does the same through the "Personality of the Year" voting, where audience feels important and heard. All these engagement features are open and do not require prior registration, making it easier for the audience to chip in. Other features are "News of the Day" or "Personality of the week", which also attract participation and voting online. 
Some TV Programs ask viewers to comment or ask questions for their guests (Opinion, Xing me Ermalin, Top Show). The news items have also started to add comments by the audience members within the body text of the news. This is a clear suggestion of a significant advancement in audience-generated content (especially news related to the weekly communication of the countries' prime minister with the public via Facebook).

This is a new development in the journalistic discourse, bringing the audience into the newsroom without being present there. It's a positive development which is gaining ground fast, but it does not mean a loss of control over media and journalism discourses. As Borger and Sanders (2014) argue, media, the broadcaster, is still the gatekeeper and has the final say over content process and its output. And is the journalist or the editors who decide which comments will be included and in which context in the media. However, commentators have brought a new perspective on media news, program and the full picture of what is being broadcasted and ultimately goes to the audience, much richer and with multiple points of view.

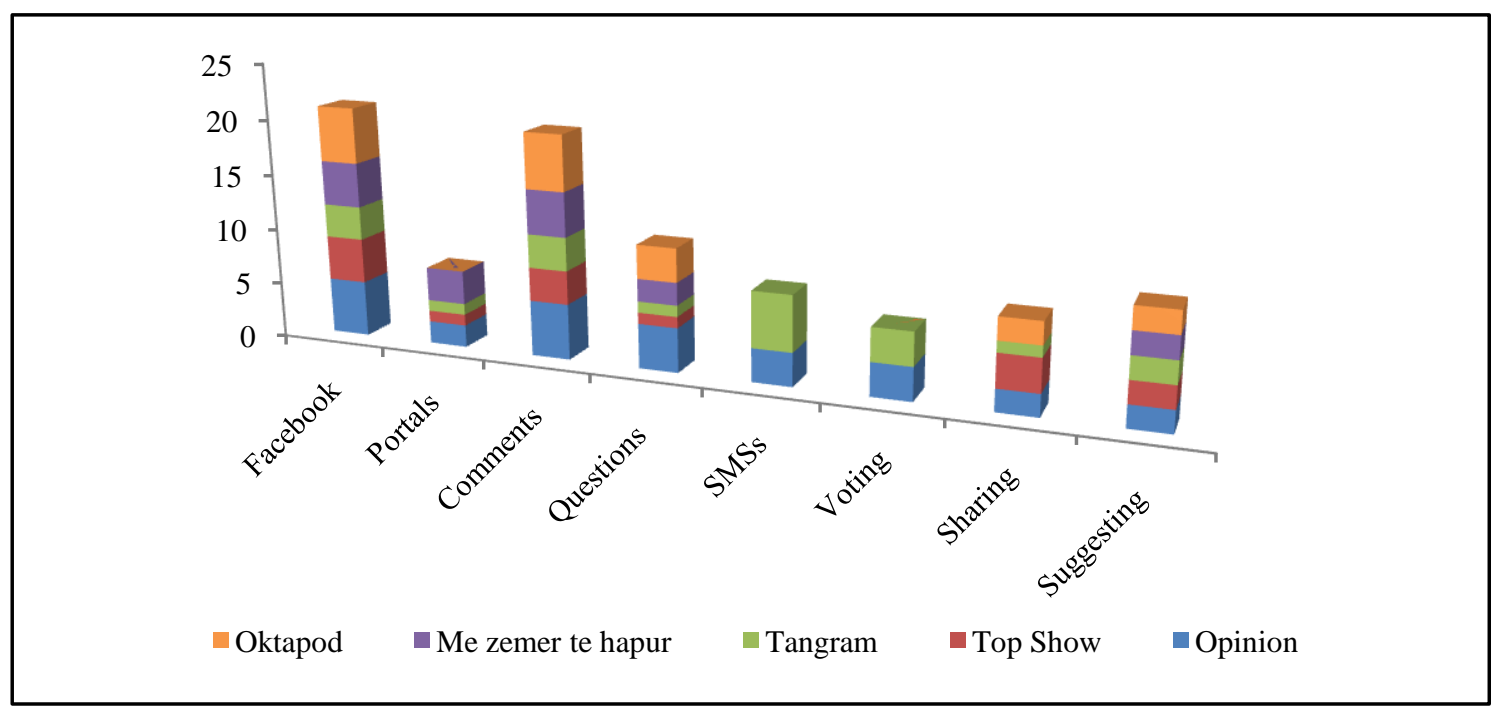

Figure 3. Types of audience engagement as cizitens.

As Figure 3 shows, even in the participatory opportunities as citizens, audience prefers commenting and sharing in Facebook, followed by voting and suggestions when applicable.

In the electoral campaigns of 2013 and 2015, a new frequency of audience participation emerged, as the TV stations provided online communication tools to ask questions to the political candidates. Selected comments and questions sent by the audience members to the Facebook accounts or SMSs in the studio were asked to the guests during the campaigns. Television stations broadcasted also features from electoral meetings where the audience asked questions directly to the candidates.

These new formats of electoral meetings with the audience sitting in semi-circles and discussing with candidates, gave a new meaning to the participation in political meetings, and more importance to the attendees. The format brings a new approach to citizen's participation in public affairs, giving a voice to audience interests and pushing politicians to think, act and respond on tough questions and issues that concerns the citizens. Unfortunately, this tactic is not echoed in the media. Despite the new approach in the meetings outdoors across the country, little time was actually given to the audience for comments and input. In the news programs, the central point of broadcast remains the political representatives, missing thus the opportunity to mediatise the approach as a new way of democratic engagement. 
There is a new practice of appointing an Audience Ombudsperson in the media in some countries, like Spain and Portugal, as a mechanism that connects the media with its audience and it increases its participation. This is a new tool used in the media and it serves also as a liaison position linking users' expectations, ideas and understanding about truthfulness of the discussion, precision, balance, reality, facts and figures. This new feature of media serving public together with the public, is not yet applied in Albania, although it is a clear expression of using audience as citizens and benefiting from the users participation in the programs. However, there are indication of media staff playing a role similar to the Audience Ombudsperson. These are the journalist in charge of the Facebook page of TV programs, such as Opinion.al or Oktapod.

The journalists are the ones who respond daily to messages, comments, suggestions and queries from the audience. They sparkle debate with posts and statements, provoking increase in audience participation with comments. These same staff invite users to ask questions for forthcoming programs and ask them to vote for their favourite question. The journalists even answer audience questions and held meeting with audience members if they ask so from a program.

\section{Activists: One Step Ahead Towards Independence From the Media}

Organisation and participation does not happen in the media only. The new technology has given the opportunity to activists and social movements to become free of media dependency, to distribute their content and become their own medium to raise their concern. Social media has given the opportunity to social movements to open new channels of communication, political action, association and initiatives.

In October 2016, a groups of social activist organised protests and concerts to manifest the opposing spirit against hydropower built in Northern Albania. Media ignored the movement and kept the focus on the political broadcast, guarding the tie with the representatives of the government against whom the protest were taking place. However, continuous share on social media and participation of high profile personalities from the Albanian diaspora, made the event visible, effective and meaningful. Participation in social movement grew further when videos and images from the concert and protest were shared among media personalities on their personal accounts in social media. This activism against the traditional media support is strengthening citizen participation and providing visibility to the real aims and actions of audience members who participate in social movements.

A good example is the concert called "Mos ma prekValbonën" (Do not touch Valbona), an awareness raising concert aiming at stopping government's decision to build hydropower in river Valbona, north of the country, considered a rare touristic spot by the audience. As the concert was taking place in one of the main squares in Tirana and attended by hundreds of participants, traditional media was broadcasting live the prime minister's statement on the politics of the day. Through social media sharing of videos and livestreaming from the concert the audience became so big and visible that news channels Ora News and News 24 (included in this research), slowly moved from half screen to each event, to the full screen broadcast of the concert/protest. This is a clear example of how activism can push media to practice standards or inclusion, participation, respect, time, space and balance for all.

As Figure 4 shows, after social media posts and shares, and with the increased interest of audience in the protest, mainstream media reflected on the momentum and started to broadcast, with two encounters of live coverage from two TV stations, flash coverage in news edition in all TV stations included in the research and a full new report in three out of the five TV channels examined. 


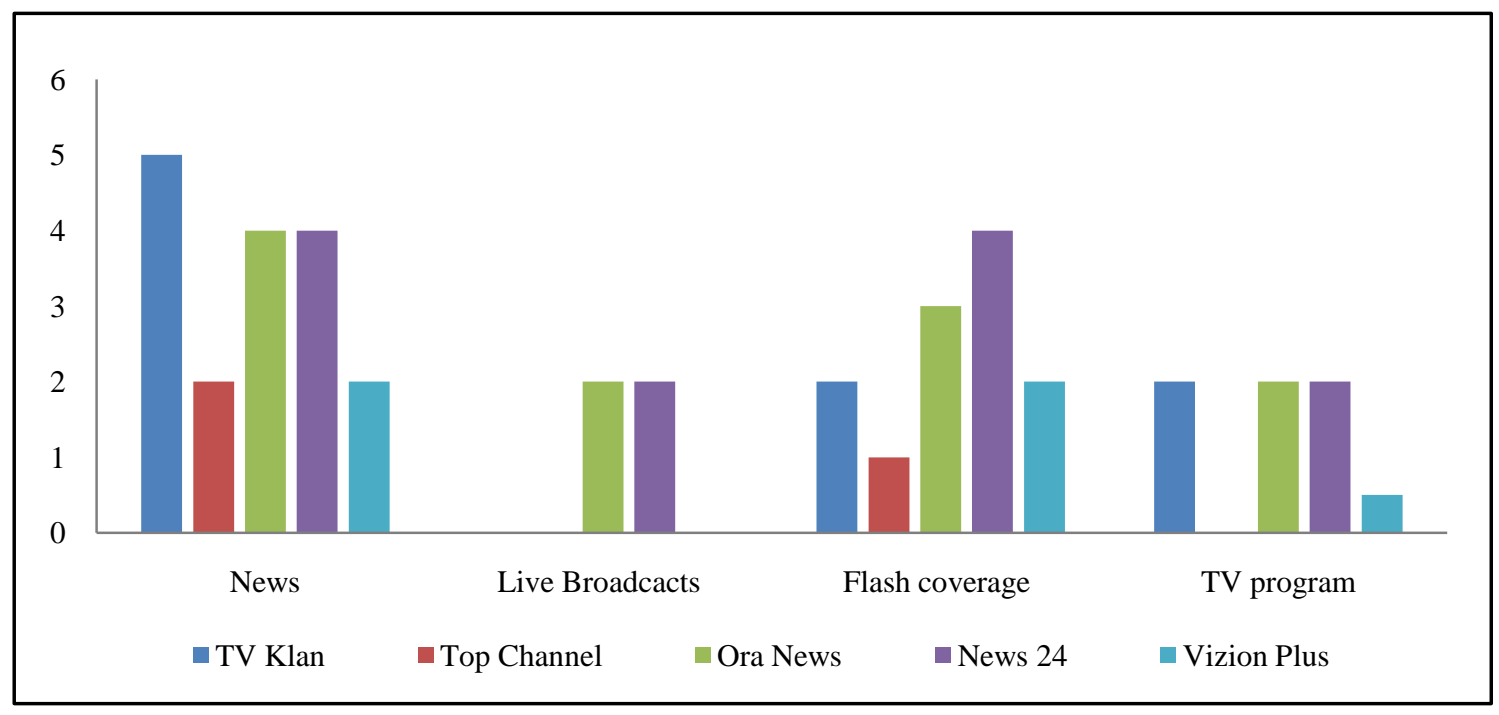

Figure 4. Number of media boradcasts encouraged by social activists.

\section{Results}

Four main types of audience participation can be detected in Albanian media and the webpages of the TV channels included in this research: consumer, commentators, citizen and activists. The scale of audience participation is growing and audience ranking is no longer an indicator of success for the future in all media programs. Apart from the central quantitative question: "How many people watch us?" TV program are now focusing on "How the audience interprets us?" Research in the audience behaviour and participation shows that viewers are familiar and advanced in using engagement tools, with the aim to become part of the content and meaning making of television, especially when it comes to political programs. Audience is no longer happy or at peace by standing still, being numbered and watching. They want to share, comment, suggest, ask, and participate. Viewers can even contribute to media content and shift its streaming, as explained in this paper.

\section{Other Types of Audience Users Observed}

Some audience members respond to the appeal to send audio-visual contributions to the media. And even if they don't, now media can take full advantage of the technological development. As soon as a significant event is recorded and posted in Facebook pages, web portals are fast to copy the upload and redistribute it, often without permission or notification to the author.

This is the type of collaborative viewer, even though at times these viewers are not aware of the contribution offered. Other types of collaboration is to send pictures, text or images to various media topic such as "Best spot in Albanian Riviera" (Top Channel) or "My pet is the best" (Club FM).

Another type of audience engagement is seen in the form of frequent share of posts asking donations and financial support for severe health issues of unknown people from disadvantaged families. Journalists are often contacted by family members of people in need and they share concerns and appeal for help from audience members. "Njëfundjavëndryshe" (A different weekend) is also a case of audience engagement through social media used by journalists and media representatives. By sharing the activities of this initiative, more and more audience members are joining the group of unknown, voluntary people who gather food, clothes and amenities every weekend and deliver them together to families in need across the country.

Ora News broadcasts a program called Tangram, devoted to children's ideas of a better Albania. This 
initiative fulfils the objective of becoming a social model, as children are put in the centre of the program and provide fully developed ideas and projects on various topics that would make the country safer and better for them, like road signs, city litters, pedestrian crossing, school yards, etc. Audience is invited to participate in the program by voting for the best project, which is in turn presented to public authorities for possible implementation.

There are also other ways of engaging the audience, like team play in various games in the studio, or inviting the audience to play in presenter-led quiz programs. In this case, the presenter encourages the participation in the show, entertains viewers and fosters educations layers through quizzes about current affairs, history, culture, sport, etc., as it is the case in the Top Channel Program, 100 Milionë.

Voting is a common strategy to keep the viewers active in TV programmes, and at times, voting has been expensive compared to normal phone charges for simple SMS (Voice of Albania and Big Brother). Also, allowing the audience to have the final say in the casting vote is a good way to keep high the audience's motivation and interest to say committed to the program. Voting remains a good way to generate additional income for the TV channels and they play quite well the part of making viewers believe in the decisive role to influence the results of any given program.

Using fan pages and chats is another new trend in the media. However, it is mostly individual programs, rather than TV channels, which rely on this participatory feature to promote their content. With this innovative approach, TV programs engage the audience by providing interviews or photos with celebrities, tickets to TV shows or premieres, comment in real time and live during the program, comments and feedback about live music shows (i.e., KëngaMagjike, Big Brother and News rooms). Top Channel invites audience members to send their ideas, videos and creations to their shows, so that producers can offer their feedback. These are all initiatives that allow media programs to strengthen the interconnection and relations with their users.

\section{Conclusions}

In the chain of communicating, for many years the message has gone from sender to receiver in a one-way direction. In the media studies, audience participation is explored as innately beneficial and as naturally generating positive outcome for citizens and the society (Livingstone, 2013; Carpentier, 2011). The importance of the "informed citizen" and the effects or relations of citizens' engagement with the media are central to the media studies examining participatory audience (Curran, 2011). The new developments of technology and the internet, brought significant changes in the receiver's role.

Audience is participating in many ways in the communication process and new opportunities of participation are available in the media, causing a reshape in the academic discourses about audience and citizen participation in the media (Carpentier, 2011; Press \& Williams, 2010). This feedback is empowered by technological innovation that enables an increasing variety of audience participation and contribution to media content. Discourse on audience has moved from audience as a consumer, to active audience connecting with the media and integrating ideas from public journalism (Friedland \& Nichols, 2002).

In the recent years, the research is focused on participatory theories that encourage content generating and the expansion of citizen's access to media production and distribution (Jenkins, 2006), still relying on the technological developments and the Internet-based exhilaration on the new millennium (Curran et al., 2012). Literature shows that there is an agreed assumption among scholars that citizens do want to be active practitioners, and this is elaborated under the positive light participation as a societal objective (Bruns, 2008; 
Mouffe, 2005).

Participation is intently conceptualised separately from interaction, and by doing so, Carpentier (2011) refers to participation as a full involvement that holds some level of power in the decision-making process. It has also been argued that the level of citizen' participation with the media is related to the level of public engagement of every citizen (Couldry et al., 2007). However, despite the numerous participating tools, the audience is not as active as anticipated by academics 15 years ago (Newman \& Levi, 2013). Audience members choose to take little advantage of the media engaging practices and the most encountered form of participation is commenting on TV programs and occasionally, showing signs of active citizens' examples.

However, a new way of media and audience relations can be observed, as the mobile phone users and new mobile applications allow interaction with media channels and interventions in the media messages and content. Audience is even gaining a degree of independence from the media, as social networks now give a voice to every social movement.

Viewers' engagement with the media is no longer limited to watching passively in the studio or calling on the phone from home. Interaction is now possible though many new features and applications that enable voting, asking, commenting, pointing out, suggesting, participating, performing among others. Broadcasters now have websites and very active Facebook pages in an attempt to adapt to the way media consumption and interaction is taking place. Viewing and consuming patterns have changed, and so has the media approach and understanding of the viewer.

The activities, programs and TV channels analysed in this article show new and fast adapting ways to participation platforms related to audience as consumer, citizen, commentator and activist. The trends has shifted from targeting audience as consumer, to new ways of using the viewers' potential in content, as well as in income for the networks.

From the social change perspective, examples show that participation of individual as citizens to the media content emphasises the contribution of viewers in improving the quality of the program, to increase participation for all and to increase the values of the public sphere.

Audience members are now more aware than ever of their potential to influence media content, and they are taking the opportunity to discuss, exchange ideas, comment and sparkle debate at all levels, from TV studios to political life and decisions.

Commentators and followers are shaping the new relations between media and the audience, as the media reflects on the gaps and sources offered by the viewers. Audience is also contributing with amateur, audio, video and images, generating content and increasing the program's dynamism. In the active audience member, media has now an ally and a rival at the same time.

These members are the ones who enable social movements and proceed without the need to be supported by the media. They make their cause known publically by the social media, influencing thus directly in traditional media shift of the program, to keep up with the dynamics of their actions and excellent use of livestreaming (Jenkins et al., 2013).It is in the broadcasters' interest to reach and collaborate with the activist type of viewers who are committed to media production and effect.

Despite the growing number of ways to interact with its audience, it still remains unclear how media manages the whole contribution of the viewers. More transparent tools are required to improve the communication with the audience and to make full use of the received contribution. The increased interaction of audience with the media and its online platforms is shaping the structure, content and production of media 
programs, to meet the new developments in audience participation and expectations.

Audience participation is dominant in the online platforms. Television remains the passive medium that communicates with a silent viewer. However, in the new era of technological advances and Internet, television cannot survive without online platforms where viewers can interact and influence the content, programming, design, format and even schedules of the media.

Participation devices have encouraged an increase in participation aim and activism of the audience, therefore, further research is needed to explore the interaction and mutual influence of producers and viewers in the increasingly collaborative environment. And this interconnectedness cannot be ignored, as audience participation is more than ever a necessity for the future of television and media programs.

\section{References}

Adams, J. W. (2008). Innovation management and U.S. weekly newspaper websites: An examination of newspapers managers and emerging technology. The International Journal of Management, 10(4), 64-73.

Anderson, L. (2011). Demystifying the Arab Spring. Retrieved from https://www.foreignaffairs.com/articles/libya/2011-04-03/demystifying-arab-spring

Bachmayer, S., Lugmayr, A., \& Kotsis, G. (2010). Convergence of collaborative web approaches and interactive TV program format. International Journal of Web Information System, 6(1), 74-79.

Bauman, S., \& Hasenpusch, T. C. (2016). Multiplatform television and business models: A Babylonian clutter of definition and concepts. Westminster Papers in Communication and Culture, 11(1), 85-102.

Borger, M., van Hoof, A., \& Sanders, J. (2014). Expecting reciprocity: Towards a model of the participants' perspective on participatory journalism. Retrieved from http://journals.sagepub.com/doi/pdf/10.1177/1461444814545842

Bruns, A. (2008). Blogs, Wikipedia, second life and beyond: from production to produsage. New York: Peter Lung.

Butsch, R. (2008). The citizens audience: Crowds, publics, and individual. New York: Routledge.

Caldwell, J. T. (2006). Convergence television: Aggregating form and repurposing content in the culture of conglomeration. In L. Spigel, \& J. Olsson (Eds.), Television after TV: Essays on a medium in transition (pp. 41-74). Durham, NC: Duke University Press.

Carpentier, N. (2001). Managing audience participation: The construction of participation in an audience discussion programme. European Journal of Communication, 16(2), 209-232.

Carpentier, N. (2011). Media and participation. Chicago: The University of Chicago Press.

Castells, M. (2010). Communication power. Oxford: Oxford University Press.

Cesar, P., \& Geerts, D. (2011). Understanding social TV: A survey. Proceedings from http://homepages.cwi.nl/ garcia/material/nem-summit2011.pdf

Colapinto, C. (2010). Moving to a multichannel and multiplatform company in the emerging and digital media ecosystem: The case of Mediaset Group. International Journal of Media Management, 12(2), 59-75.

Costera Meijer, I. (2005). Impact or content? Rating vs. Quality in public broadcasting. European Journal of Communication, 20(1), 27-53.

Couldry, N. (2004). The Productive "consumer" and the dispersed "citizen". International Journal of Cultural Studies, 7(1), 21-32.

Couldry, N., Livingstone, S., \& Markham, T. (2007). Media consumption and public engagement. New York: Palgrave Macmillan.

Curran, J. (2011). Media and democracy. London: Routledge.

Curran, J., Fenton, N., \& Freedman, D. (2012). Misunderstanding the Internet. New York: Routledge.

Curtin, M. (2009). Matrix media. In G. Turner, \& J. Tay (Eds.), Television studies after TV: Understanding Television in the post-broadcast era (pp. 9-20). London: Routledge.

Deery, J. (2003). TV.com: Participatory viewing on the web. Journal of Popular Culture, 37, 161-183.

Domingo, D. (2008). Interactivity in the daily routines of online newsrooms: Dealing with an uncomfortable myth. Journal of Computer-Mediated Communication, 13(3), 680-704.

Dowland, P. S. (2016). Advances in Communications, Electronics, Networks, Robotics and Mathematics. School of Computing and Mathematics, Plymouth University. 
Doyle, G. (2010). From television to multi-platform: Less from more or more for less?. The International Journal of Research Into New Media Technologies, 16(4), 1-19.

Doyle, G. (2015). Guest editor's introduction to the special issue: Multi-platform strategies. Journal of Media Business Studies, $12(1), 3-6$.

Dvorak, J. (2012). Why IPTV is the future. PC Magazine (p. 1).

Friedland, L. A., \& Nichols, S. (2002). Measuring civic journalism Progress: A report across a decade of activity. Retrieved from http://cdm16064.contentdm.oclc.org/cdm/ref/collection/p266901coll4/id/978

Garcia-Aviles, J. A. (2010). Citizen Journalism in European television websites: Lights and shadows of user generated content. Observatorio $\left(O B S^{*}\right), 4(4), 360-382$.

Herreros, C. M. (2004). Modelos de television: Generalist, tematica i convergente con Internet. Barelona: Paidos.

Holmes, S. (2004). But this time you choose! Approaching the "interactive audience in reality TV". International Journal of Cultural Studies, 7(2), 213-231.

Jakubowicz, K. (2008). Participation and partnership: A Copernican revolution to reengineer public service media for the 21 st century. RIPE: Germany.

Jenkins, H. (2006b). Fans, Bloggers and Gamers: Exploring participatory culture. New York: New York University Press.

Koltay, T. (2011). The media and the literacies: Media literacy, information literacy, digital literacy. Media, Culture and Society, $33(2), 211-222$.

Livingstone, S. (1998). Audience research at the crossroads. European Journal of Cultural Studies, 1(2), 193-217.

Livingstone, S. (2013). The participation paradigm in audience research. The Communication Review, 16(1-2), 21-30.

Livingstone, S., Lunt, P., \& Miller, L. (2007). Citizens, consumers and the citizens-consumers: Articulating the interests at stake in the media and communications regulation. Discourse and Communication, 1(1), 85-11.

Marshall, P. D. (1997). Celebrity and power: Fame in contemporary culture. Minnesota: University of Minnesota Press.

Martinez, J. S. (2015). Citizens and online media participation: Attitudes and motivations towards journalism and other online practices in London and Barcelona. School of Communication and International Relations, Universitat Ramon Llull.

Mouffe, C. (2005). On the political. London: Routledge.

Newman, N., \& Levy, D. (2013). Digital News Report 2013: Tracking the future of news. Oxford: Reuters Institute for the Study of Journalism.

Nightingale, V., \& Dwyer, T. (2006). The audience politics of "enhanced" television formats. International Journal of Media and Cultural Politics, 2(1), 25-42.

Press, A. L., \& Williams, B. A. (2010). The new media environment: An introduction (p. 240). Oxford: Wiley-Blackwell.

Roscoe, J. (2004). Multiplatform event television: Reconceptualising our relationship with television. Communication Review, 7(4), 363-369.

Rosen, J. (2006). The people formerly known as the audience. Retrieved from http://archive.pressthink.org/2006/06/27/ppl_frmr.html

Schaefer, M. T. (2011). Bastard culture! How user participation transforms cultural production. Amsterdam: Amsterdam University Press.

Siapera, E. (2004). From couch potatoes to cybernauts? The expanding notion of the audience on TV channels' websites. New Media and Societies, 6(2), 155-172.

Singer, J. B., Hermida, A., Domingo, D., Heinonen, A., \& Qauandt, T. (2011). Participatory Journalism guarding open gates at online newspapers. Oxford: Wiley-Blackwell.

Steensen, S. (2011). Cosy journalism: The rise of social cohesion as an ideal in online, participatory journalism. Journalism Practice, 5(6), 687-703.

Syvertsen, T. (2004). Citizens, consumers, costumers and players: A conceptual discussion of the relationship between the broadcasters and their publics. European Journal of Cultural Studies, 7(3), 363-380.

Thorsen, E., \& Allan, S. (2014). Citizen Journalism: Global perspectives. New York: Peter Lang.

Usher, N. (2011). Professional Journalists, Hands Off! Citizen journalism as civic responsibility. In R. McChesney, \& V. Pickard (Eds.), Will the last reporter please turn out the lights: The collapse of journalism and what can be done to fix it. New York, London: The New Press.

Villi, M. (2012). Social Curation in audience communities: UDC (user-distributed-content) in the networked media ecosystem. Journal of Audience and Reception Studie, 9(2), 614-632.

Webster, J. G., \& Phalen, P. F. (1997). The mass audience: Rediscovering the dominant model. Mahwah, Nj: Lawrence Erlbaum. 